\title{
Ethical dilemmas when dealing with doctor Google and the importance of patient education
}

SADJ November 2019, Vol. 74 No. 10 p582 - p585

LM Sykes ${ }^{1}$, E Crafford ${ }^{2}$, C Bradfield ${ }^{3}$, C Johnson ${ }^{4}$

\section{CASE REPORT}

A 55 year old female patient presented for dental treatment. Her attending clinician immediately noted that since her first visit some days previously she had shaved her head, revealing a severe rash on her right forehead and scalp (Figure 1).

The rash extended from her right eye inferiorly to the coronal suture superiorly. It ended abruptly in the midline mesially and along a distinctly demarcated line just above her ear laterally.

The entire area of skin within these borders was fiery red with many large crusted areas. Her right iris was also reddened and the eye itself watery (Figure 2).
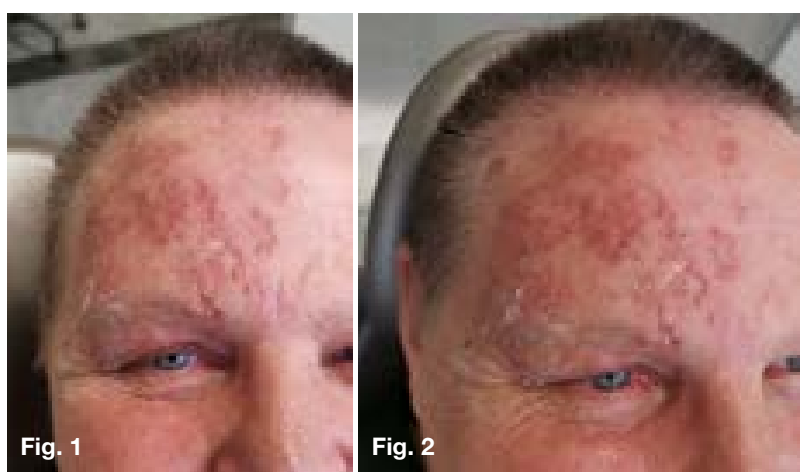

Figure 1. Unilateral spread of skin rash.

Figure 2. Ocular involvement of viral infection.

Photographs printed with kind permission of the patient.

\section{Author affiliations:}

1. Leanne M Sykes: SBSc, BDS, MDent, IRENSA, Dip Forensic Path, Dip ESMEA, Head of Department of Prosthodontics, University of Pretoria, South Africa.

ORCID Number: 0000-0002-2002-6238

2. Elmine Crafford: $B C h D, B C h D$ Hons, Oral Medicine, MChD OMP, Senior Specialist Department of Oral Medicine and Periodontics, University of Pretoria, South Africa.

3. Charles Bradfield: B Tech, BChD, Dip Aesthetics, Registrar Department of Prosthodontics, University of Pretoria, South Africa.

4. Chalita Johnson: $B C h D$, Final year dental student, University of Pretoria.

Corresponding author: Leanne M Sykes

Head Clinical Unit, Department of Prosthodontics, University of Pretoria, South Africa.

Email: leanne.sykes@up.ac.za

Author contributions:

1. Leanne M Sykes: Primary author - $40 \%$

2. Elmine Crafford: Secondary author $-30 \%$

3. Charles Bradfield: Student supervisor $-20 \%$

4. Chalita Johnson: Treating student $-10 \%$

\section{ACRONYM}

VZV: Varicella-Zoster Virus

On questioning, she reported that about a week earlier she had developed a sudden and severe headache with itching of her scalp. She had taken some aspirin for the pain and rubbed Aloe Vera gel on her head to try to calm the itch. Almost immediately she noticed that her entire body started to become hot and itchy.

She rushed to her pharmacist who diagnosed a severe allergic reaction to the gel and gave her a dose of corticosteroids. This helped with the reaction and itch on her body, however the head rash persisted and worsened over the next few days.

The dentist was skeptical about this diagnosis especially in light of the persistent lesions and their distinct unilateral location. On further questioning she revealed that she had been feeling very tired that day and was sitting in the sun resting when the symptoms developed. Given the history, reported signs and symptoms, and classical appearance of her condition, the dentist suspected that she had been mis-diagnosed, and that she was suffering from an intense case of varicella-zoster virus (VZV) infection, worsened by an allergic reaction.

The patient was informed about the aetiology and pathophysiology of this viral infection. During this process of patient education, she remembered more of her own details, which all conformed to the classic picture of VZV infection. (For a brief description see ** on p584). She was advised to visit a medical practitioner, but chose to rather wait and see how she felt. Fortunately her lesions resolved slowly and uneventfully over the following five weeks.

This case scenario illustrates the commonly seen situation where patients first self-diagnose and self-medicate, and only later seek help if their symptoms don't improve. Her initial use of the Aloe gel led to an allergic reaction that the pharmacist subsequently treated with cortisone.

While this was appropriate for the allergy, he did not look deeper into the history of her complaints and failed to identify the very obvious VZV lesions on her head. 
Had he done so, he should have known that cortisone is contra-indicated in viral infections as it suppresses the immune system and thus makes it harder for the body to fight the virus., ${ }^{1,2}$ As expected, her infection worsened.

When she arrived at the dental clinic, the dentist was the first to take a thorough history including an extraoral and intra-oral examination. She recognized all of the indicators that suggested the patient was suffering from a VZV infection, and advised her to go for further allergy tests as well as a thorough medical check up to confirm her suspicions.

Unfortunately, at this stage nobody had paid much attention to the fact that the virus had already invaded the optic nerve which could lead to scarring or even blindness. Had she been sent for special tests immediately, she could have been given antiviral medication to prevent this potentially sinister spread.

\section{Ethical questions that need to considered}

In this case the pharmacist diagnosed and prescribed medication for a condition that he was not trained to manage. In addition steroids are classified as Schedule 4 drugs and should only be dispensed with a doctor's prescription. The remedy alleviated some of her symptoms, but they also aided the progression of the far more serious viral infection.

It draws attention to the issue of patients seeking advice and being treated by non-trained persons, including themselves, family, friends, social media sites, magazines, television shows, traditional healers, "alternative medicine" practitioners, and even other medically trained person who act outside their areas of expertise.

A number of questions arise such as:

- Who can and should be allowed to make medical / dental diagnoses, and dispense medication?

- Who is accountable for the consequences of treatment where an incorrect initial diagnosis was made and the wrong medicine was prescribed?

- If a patient makes an autonomous decision to consult someone other than a doctor for medical advice and care, do they have the right to lay charges against the former if their conditions worsen? This is particularly relevant in this case where the drug prescribed for the management of the allergy was correct, however the pharmacist failed to diagnose the VZV, a condition in which the same medication is totally contra-indicated?

- What should the dentist have done at the first consultation? Treatment of VZV is generally not within their scope of practice unless there are oral symptoms, which often do not resemble classic skin VZV.

- Should the dentist attempt to aspirate the fluid in oral lesions or take swabs, or rather send directly to a medical practitioner?
- Should the dentist provide symptomatic relief by prescribing pain killers? However, this too could be risky given that the patient had a history of a recent allergic reaction.

- Can someone who posts advice on Google / social media sites be held accountable if others follow their suggestions and there are harmful consequences?

- Does and should the Consumer Protection Act cover the dispensing of services and medication?

Reasons why patient may seek alternative treatment

It is tempting to chastise patients who don't go to their doctors initially, or even after being advised to do so. However, there are many reason why they may not go for help or may seek unconventional/alternative therapy. This may be a conscious decision, or could be a choice made as a consequence of circumstances.

Patients may have time and financial constraints which prevents them from seeking and/or affording medical services; unequal access to health care; living in remote areas where there is a scarcity of doctors, limited resources and lack of medication; lack of education; fear and skepticism of modern medicine (Ahmed Bawa anti-intellectualism and distrust in science is a growing international trend); trust in local figures who are considered to be knowledgeable; previous bad encounters with medical professionals, desperation if conventional treatment has been unsuccessful; and in some cases they do not want to know the truth or severity of their condition, and choose to self-treat or to hide their symptoms.

The onus often lies with the advice-giver to recognize their own limitations, to be modest enough to know when to refrain from treating, and to have the wisdom to detect when a patient needs to be referred to a more experienced practitioner.

Another concern is the ease with which patients can access medicine without needing a prescription. They may acquire it from friends, from a friendly pharmacist, or even through the internet. The latter is particularly dangerous as there are many counterfeit products on the market, often available at temptingly low prices which entices naive customers.

\section{Issues for the dentist to consider?}

The dentist has a number of issues to consider:

- How to deal with the pharmacist who tried to help, but at the same time acted negligently by failing to take a full history and thus not only made an incorrect diagnosis, but also missed identifying the more crucial primary condition?

- What to do about the pharmacist who wrongly providing medication that was totally contra-indicated for her condition, and more than likely exacerbated her symptoms? 
- What advice to give the patient about the treatment she had received, and whether or not she should take any actions against the pharmacist, given that she was the one who sought his help?

- How to manage the patient at that first visit, for she needed to have the VZV infection definitively diagnosed and managed urgently as it had already spread to involve her right eye?

- If the dentist intervened and provided medication, but the patient did not recover, could he/she be held responsible for both the initial incorrect treatment as well as the intervention?

- Should the dentist approach the pharmacist directly or advise the patient to either report back to the pharmacist or lodge a complaint against him?

Given that the patient was reluctant to take the dentist's advice to consult a doctor, and she still maintained that her pharmacist had helped her, she probably would not approach him. She may also not want to jeopardize her future supply of easily accessible, "OTC-prescription" medication.

However, the outcomes of this sort of practice by the pharmacist may not always be favourable, and could even have dire consequences. The dentist, who is also a health care provider, has an ethical duty to promote beneficence and non-maleficence (i.e. prevent harm), and is obligated to take actions to enhance the health and safety of all patients.

\section{Possible steps to follow}

- Document the patient's present condition (including photographs) at that visit.

- Refer the patient to a more suitably trained medical person to confirm the diagnosis, and record this in the event that she chooses to not seek help.

- Inform and educate the patient about her condition, the dangers of self-diagnosing or relying on internet sites and other ill-equipped persons for information, and the risks of taking unprescribed medication.

- Follow up on the patient's condition if possible. This may be difficult if he/she does not come back for further dental treatment.

- Warn the patient about possible adverse drug interactions, especially if they take OTC medication or take a cocktail of drugs they have procured from various sources.

- Consider calling the pharmacist to discuss your concerns in a collegial manner. Remember though, the obligation to maintain patient confidentiality and anonymity.

Thus it may be prudent to inform the patient of your intention and ensure that her identity is protected when you discuss her case.
- If the pharmacist's prescribing habits are seriously dangerous or frequent, one may consider reporting the matter to the HPCSA.

The flip side of this is that we have very little control over similar situations where medication is provided by traditional healers, homeopaths, alternative therapists or purchased off the internet, so one could argue that at least the pharmacist has a medical background and training.

\section{CONCLUSIONS}

This case is a reminder that dentists need to be holistic in their approach to treatment and to see beyond the mouth. They have a duty to spend time taking a comprehensive history, and in conducting a thorough extra-oral and intra-oral examination.

It is also incumbent on them to be responsible for educating their patients and colleagues, and to acknowledge and embrace alternative healers. They need to also stand together as active campaigners in the fight against the illegal supply and use of all forms of medicine.

In conclusion, in ethics and in practice, there are often no clear answers as to what the practitioner should have done in this situation. In addition, their actions may not be the same in each situation or between patients. What do other practitioners think and feel?

\section{References}

1. Rostaing L, Malvezzi P (2016). Steroid-based therapy and risk of infections complications. PLos Med; 13(5): e1002025. https://doi.org/10.137/journal.pubmed.1002025.

2. Gnann JW (2007). Antiviral therapy of varicella=zoster virus infection. From: Human herpesvirus: Biology, Therapy and Immunoprophylaxis. Cambridge University Press. Eds: Arvin A, Campadelli-Fiume G, Mocarski E; 65.

\section{${ }^{* \star}$ Varicella Zoster Virus}

The rash is typically preceded by a prodromal stage in which the patient may experience a painful tingling, itching, hyperesthesia, or paraesthesia which is confined to one area. ${ }^{1,2}$ This is often accompanied by fever, headache, or fatigue, and followed by the emergence of a characteristic skin rash along the affected dermatome resulting in a reddened stripe that is limited to one side of the body and does not cross the midline. ${ }^{1,3,4}$

Later the rash forms small vesicles filled with a serous exudate, which become cloudy and darkened as they fill with blood, and finally they crust over. ${ }^{4}$ The rash usually heals within two to four weeks; ${ }^{2}$ however, some people develop "ongoing nerve pain which can last for months or years, a condition called post herpetic neuralgia (PHN)". ${ }^{1}$ Reactivation of VZV results in shingles which may become widely disseminated in the elderly or those with compromised immune function. ${ }^{1}$

Shingles of the head most frequently affects the trigeminal nerve. ${ }^{5}$ When the ophthalmic division is involved it will affect the skin of the forehead, upper eyelid and 
orbit of the eye. ${ }^{6}$ Symptoms may include conjunctivitis, keratitis, uveitis, optic nerve palsy and even loss of vision. ${ }^{7}$

If it involves the maxillary or mandibular division of the trigeminal nerve it will manifest in the mouth as a rash on the mucous membrane of the palate, and/or gingiva or the tongue and mandibular gingiva respectively. "Oral involvement may occur alone or in combination with a rash on the skin over the cutaneous distribution of the same trigeminal branch."

"Once again lesions are confined to one side of the mouth, distinguishing it from other oral blistering conditions." Unusual complications may occur with intraoral shingles that are not seen elsewhere. The close relationship of blood vessels to nerves allows the virus to invade the blood vessels and compromise the blood supply, resulting in ischemic necrosis, ${ }^{9}$ osteonecrosis, tooth loss, periodontitis, pulp calcification, pulp necrosis, periapical lesions and tooth developmental anomalies. ${ }^{5}$

Treatment with antiviral medications such as acyclovir may reduce the severity of the infection if started within 72 hours of the appearance of the rash. ${ }^{3}$ However neither antivirals nor steroids seem to be of much value in controlling the rates of post herpetic neuralgia. ${ }^{10}$ Paracetamol, NSAIDs, or opioids may be used to help with the acute pain. ${ }^{3}$

\section{References}

1. Hamborsky $\mathrm{J}$ Epidemiology and Prevention of Vaccine-Preventable Diseases (13 $3^{\text {th }}$ ed.). Washington D.C. Public Health Foundation 2015; 353-74.

2. Gagliardi AM, Andriolo BN, Torloni MR, et al. Vaccines for preventing herpes zoster in older adults. Cochrane Database of Systematic Reviews. 3: 2016; CD008858. doi:10. 1002/14651858.CD008858.pub3. PMC 6516976. PMID 269 37872.

3. Dworkin RH, Johnson RW, Breuer J, et al. Recommendations for the management of herpes zoster. Clin Infect Dis. 2007; 44 Suppl 1: S1-26.

4. Stankus SJ, Dlugopolski M, Packer D. Management of herpes zoster (shingles) and postherpetic neuralgia. Am Fam Physician. 2000; 61(8): 2437-44, 2447-8.

5. Gupta S, Sreenivasan V, Patil PB. Dental complications of herpes zoster: Two case reports and review of literature. Indian Journal of Dental Research 2015; 26(2): 214-9.

6. Samaranayake L). Essential Microbiology for Dentistry $\left(4^{\text {th }}\right.$ ed.). Elsevier Health Sciences 2011; 638-42. ISBN 978-07020-4695-7.

7. Shaikh S, Ta CN. Evaluation and management of herpes zoster ophthalmicus.

8. Am. Fam. Physician. 2002; 66(9): 1723-30.

9. Glick M Burket's Oral Medicine (12 th ed.). 2014; 62-5. ISBN 978-1-60795-188-9.

10. Chi AC, Damm DD, Neville BW, Allen CM, Bouquot J. Oral and Maxillofacial Pathology. Elsevier Health Sciences. 2008; 250 - 3. ISBN 978-1-4377-2197-3.

11. Chen N, Li Q, Yang J, et al. Antiviral treatment for preventing postherpetic neuralgia. Cochrane Database of Systematic Reviews. 2014; 2 (2): CD006866. doi:10.1002/14651858.

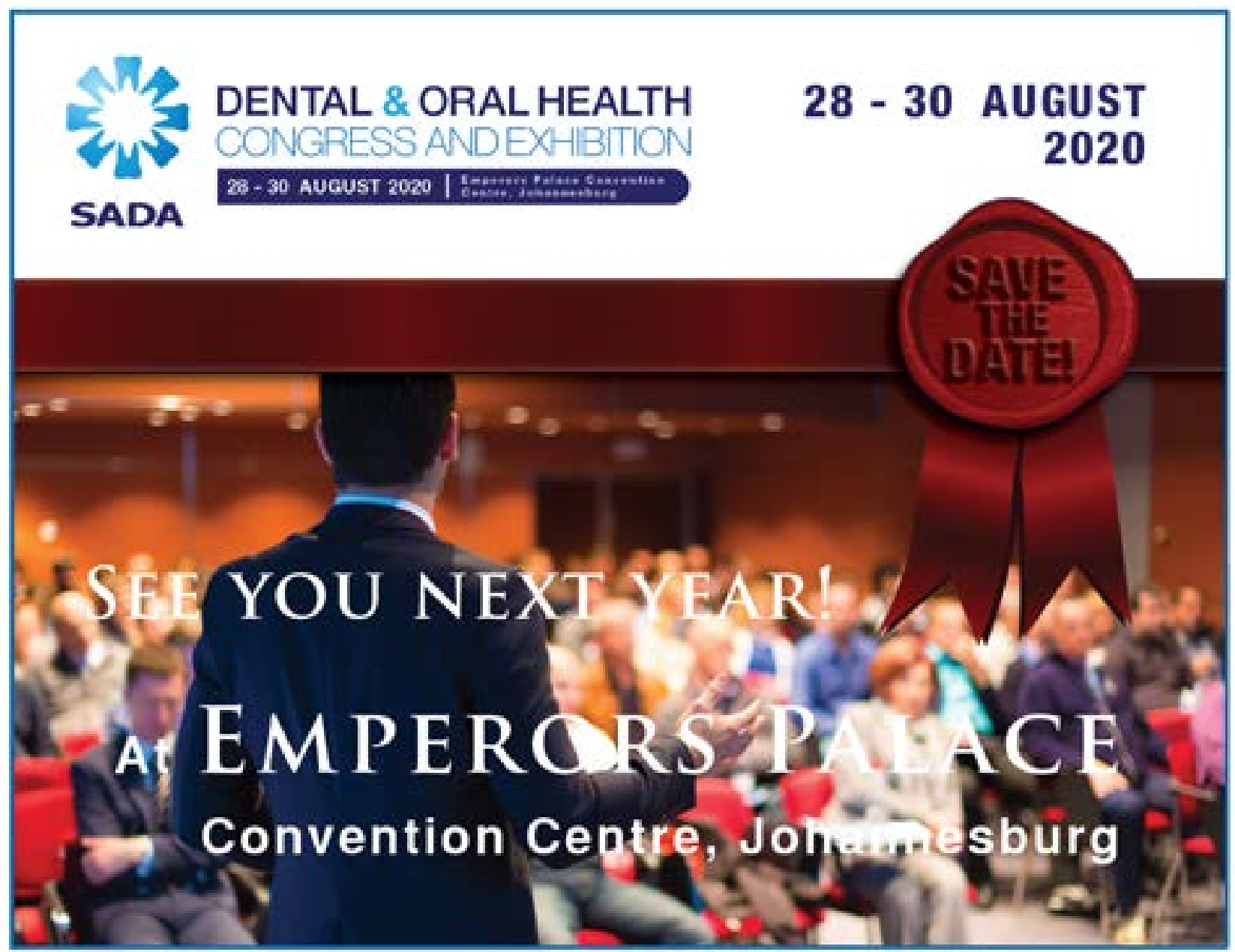

